\title{
Permeabilidade do solo em área de aterro sanitário
}

\author{
Soil permeability in a landfill area
}

Willian Fernando de Borba Professor Adjunto da Universidade Federal de Santa Maria, Campus Frederico Westphalen - RS, Brasil borbawf@gmail.com

José Luiz Silvério da Silva Professor Titular da Universidade Federal de Santa Maria, Santa Maria-RS, Brasil silverioufsm@gmail.com

Pedro Daniel da Cunha Kemerich Professor Adjunto da Universidade Federal do Pampa, Campus Caçapava do Sul - RS, Brasil eng.kemerich@yahoo.com.br

Éricklis Edson Boito de Souza Mestrando do Programa de Pós-graduação em Engenharia Florestal (PPGEF), Universidade Federal de Santa Maria, Santa Maria - RS, Brasil ericklisboito@gmail.com

Gabriel D'Ávila Fernandes Doutorando do Programa de Pós-graduação em Engenharia Civil (PPGEC), Universidade Federal de Santa Maria, Santa Maria - RS, Brasil enggabrielfernandes@gmail.com

\section{Resumo}

A geração de resíduos sólidos, consequência da mudança do modo de consumo da população, vem aumentando gradativamente com o passar dos anos. Aliado a isso, pesquisas desenvolvidas em áreas de disposição de resíduos, visando a proteção do meio ambiente, são de extrema importância. Assim, esse estudo tem por objetivo analisar a permeabilidade de um LATOSSOLO VERMELHO utilizado para um aterro sanitário empregando várias técnicas de estimativa. Para a técnica ex situ, foi determinada a condutividade hidráulica saturada em quadruplicata em um perfil de solo, aplicando um permeâmetro de carga constante. Já para a determinação in situ, foi utilizado um permeâmetro de guelph em três pontos de análise. Resultados indicaram a presença de um solo com predomínio de microporos $(52,26 \%)$, com valores de condutividade hidráulica médios de $5,09 \times 10^{-4} \mathrm{~cm} \cdot \mathrm{s}^{-1} \mathrm{em}$ solo natural e $1,27 \times 10^{-5} \mathrm{~cm} . \mathrm{s}^{-1} \mathrm{em}$ solo compactado. A permeabilidade obtida com uso do permeâmetro de guelph em solo compactado foi de $7,03 \times 10^{-5} \mathrm{~cm} . \mathrm{s}^{-1}$, valores estes semelhantes aos permitidos pelas normativas. Foi possível concluir que o solo compactado apresenta baixos valores de permeabilidade, em ambas as técnicas, consequência dos altos valores de argila além da presença dos microporos. Assim, os resultados obtidos são semelhantes a faixa permitida pela legislação vigente.

Palavras chave: Contaminação, condutividade hidráulica saturada, resíduos sólidos. 


\begin{abstract}
The generation of solid waste, as a consequence of changing in the population's mode of consumption, has been gradually increasing over the years. Also, research on waste disposal to protect the environment is of utmost importance. Thus, this study aims to analyze the permeability of a RED OXISOLS used for a landfill using various estimation techniques. For ex-situ technique, quadruplicate saturated hydraulic conductivity in a soil profile was determined using a constant load. For the in-situ determination, a Guelph permeameter was used at three points of analysis. Results indicated the presence of soil with micropore prodrome $(52.26 \%)$, with average hydraulic conductivity values of $5.09 \times 10^{-4} \mathrm{~cm} . \mathrm{s}^{-1}$ in natural soil and $1.27 \times 10^{-5} \mathrm{~cm} . \mathrm{s}^{-1}$ on compacted soil. The permeability obtained by using the Guelph permeability in compacted soil was $7.03 \times 10^{-5} \mathrm{~cm} . \mathrm{s}$ ${ }^{-1}$, values similar to those allowed by the normative. It was possible to conclude that the compacted soil presents low permeability values, in both techniques, a consequence of the high clay values besides the presence of the micropores. Thus, the results obtained are similar to the range allowed by current legislation.
\end{abstract}

Keywords: Contamination, Saturated hydraulic conductivity, Solid waste.

\title{
1. INTRODUÇÃO
}

Os solos são fundamentais para a manutenção da vida na Terra, assim, os processos que ocorrem nesse sistema, tais como, o desmatamento de florestas e a contaminação da água impactam de maneira diversificada a natureza dos ecossistemas (BRADY; WEIL, 2013), determinando a sua qualidade. Desta forma, quando o solo é mal manejado e recebe o aporte de resíduos indesejáveis, em curto espaço de tempo, poderá facilitar para a degradação do ecossistema (STRECK et al., 2008). Porém, esse sistema é considerado de grande importância do ponto de vista sanitário, segundo os mesmos autores, na função de meio de descarte de rejeitos e resíduos atuando como filtro inativador de produtos tóxicos.

Os aterros sanitários vêm ganhando ênfase nos últimos anos, devido aos inúmeros impactos ambientais negativos causados pelo descarte inadequado de resíduos sólidos urbanos. Ademais, o acréscimo da preocupação com esses impactos, inclusive os gerados por esse tipo de empreendimento, tem incentivado a aplicação de mecanismos e procedimentos que auxiliem no conhecimento e, imediatamente, na mitigação desses impactos (GOMES et al., 2015).

Os principais contaminantes oriundos de aterros sanitários são o lixiviado e a presença de metais, os quais, sem o devido manejo podem colocar em risco a qualidade natural do solo e dos recursos hídricos. Assim, a análise de diferentes atributos físicos torna-se importante em avaliações da qualidade e sustentabilidade dos solos.

A velocidade do movimento do percolado gerado pelo aterro na zona vadosa irá influenciar diretamente na capacidade do solo em restringir a passagem para as camadas mais profundas. Assim, 
Priyank et al. (2016) salienta que a permeabilidade é uma característica do meio poroso que informa sobre a facilidade com que a água flui através dos vazios interconectados.

A determinação da permeabilidade do solo é de extrema importância para a execução de projetos que necessitam da avaliação dos parâmetros de infiltração, escoamento superficial, água subterrânea, drenagem e estruturas (SINGH et al., 2020). Além disso, permeabilidade do solo tem papel fundamental na percolação do lixiviado. Rodriguez et al. (2015) afirmam que essa propriedade (meio poroso) determina a propensão de percolação de água por meio dos seus poros ou vazios. Além disso, a condutividade hidráulica saturada é uma das propriedades mais importantes para estudos de movimento de água, substâncias químicas e solutos no solo (PINHEIRO; NUMMER; RAUBER, 2017).

Desta forma, este trabalho teve por objetivo determinar a condutividade hidráulica em meio não saturado, em área ocupada por aterro sanitário, no noroeste do Estado do Rio Grande do Sul.

\section{METODOLOGIA}

\subsection{Caracterização da área de estudo}

A área de estudo é um aterro sanitário, localizado na região noroeste do Estado do Rio Grande do Sul. No que se refere à hidrografia, pertence à Região Hidrográfica do Uruguai (U) na Bacia Hidrográfica do Rio da Várzea (U - 100), conforme SEMA (2004). Já em relação ao clima, possui uma média anual de $1.900 \mathrm{~mm}$ (SOTÉRIO et al., 2005; ABNT, 1997b) bem distribuídas ao longo do ano, onde o clima é do tipo Cfa (sub-tropical úmido) conforme descrito por Moreno (1961).

Em relação aos aspectos geológicos, CPRM (2006) descreve que, na região em estudo, está presente a Formação Serra Geral (FSG), Fácies Paranapanema. Essa formação, segundo o autor, é constituída por derrames basálticos granulares finos, melanocráticos, contendo horizontes vesiculares, espessos preenchidos com quartzo (ametista), zeólitas, carbonatos, seladonita, cobre nativo e barita. Em termos geológicos/geomorfológicos pertence a Província Vulcânica da Bacia do Paraná (ROSS, 1985).

Já no que se refere à hidrogeologia, Machado e Freitas (2005) dizem que a área de estudo está inserida no Sistema Aquífero Serra Geral I (SASG 1). Segundo os autores, essa unidade hidroestratigráfica delimita-se pelos municípios de Soledade, Tupanciretã, Santo Antônio das Missões, Santa Rosa, Tenente Portela, Nonoai, Erechim e Passo Fundo, e é constituída principalmente, de litologias basálticas, amigdalóides e fraturadas, capeadas por espesso solo avermelhado. O solo local foi classificado por Borba (2016), seguindo o proposto pela EMBRAPA (2018), como um LATOSSOLO VERMELHO Distrófico (LVdf), com altos teores de argila (valores 
médios de $86 \%$ ). Em um estudo anterior realizado na área, o solo apresentou espessura variando de 3,70 a 7,5 m até encontrar um horizonte impenetrável ao equipamento utilizado para perfuração (DARIVA AMBIENTAL, 2006; BORBA, 2016).

Salienta-se que anteriormente, essa área era utilizada para cultivos agrícolas, principalmente soja, milho e trigo. No ano de 2007, a área de 7,7 hectares foi adquirida para instalação e operação do aterro sanitário. Como era uma atividade de pequeno porte, não se fazia necessária a elaboração de um Estudo de Impacto Ambiental (EIA). Em relação ao monitoramento ambiental exigido para a atividade, no que diz respeito à água subterrânea, existem quatro Poços de Monitoramento (PM) em atividade, denominados de PM01, PM02, PM03 e PM05. O PM01 fica localizado fora da área do aterro (à montante do empreendimento), e é considerado como ponto controle ou branco.

A unidade recebe cerca de 1.700 toneladas de resíduos sólidos urbanos mensalmente. Ainda, realiza o processo de triagem, compostagem e destinação final ambientalmente adequada dos rejeitos. No processo de triagem, são recuperados cerca de $16 \%$ do montante recebido, ou seja, 272 toneladas mensalmente. O restante é disposto nas células de disposição de rejeitos.

\subsection{Física do solo e fluxo de água no solo}

As análises para obtenção dos parâmetros físicos do solo, como macro e microporosidade, densidade, Condutividade Hidráulica Saturada (CHS), Capacidade de Campos (CC), Ponto de Murcha Permanente (PMP), foram realizadas no Laboratório de Física do Solo, da Universidade Federal de Santa Maria - UFSM, campus Frederico Westphalen - RS. A determinação dos parâmetros macro e microporosidade, densidade, CC e PMP seguiram os procedimentos descritos pelo Manual de Métodos de Análise de Solo (EMBRAPA, 2018). Já para a CHS, foi utilizado o permeâmetro de carga constante (MARQUES et al., 2008).

Para a granulometria e a identificação dos argilominerais, as informações foram descritas por Borba (2016) nessa mesma área de estudo. Os valores de referência para permeabilidade do solo são mostrados na Tabela 1. Além desses, foram utilizados os valores propostos pelas normas NBR 8.419/1992 (ABNT, 1992) e NBR 13.896/1997 (ABNT, 1997a) específicas para áreas de disposição dos Resíduos Sólidos Urbanos (RSU).

Tabela 1 - Coeficiente e grau de permeabilidade de solos.

\begin{tabular}{ccc}
\hline $\begin{array}{c}\text { Coeficiente } \mathbf{k} \\
\left(\mathbf{c m . s}^{-\mathbf{1}}\right)\end{array}$ & $\begin{array}{c}\text { Grau de Permeabilidade } \\
\text { (TERZAGHI; PECK, 1967) }\end{array}$ & $\begin{array}{c}\text { Tipo de solo } \\
\text { (MELLO; TEIXEIRA, 1967) }\end{array}$ \\
\hline $10^{9}$ a 1 & Alta & Pedregulhos \\
1 a $10^{-1}$ & Média & Areias \\
$10^{-1}$ a $10^{-3}$ & Baixa & Areias finas siltosas e argilosas, siltes \\
$10^{-3}$ a $10^{-5}$ & Muito baixa & argilosos \\
$10^{-5}$ a $10^{-7}$ & &
\end{tabular}


As amostras de solo foram coletadas em um perfil localizado próximo $(50 \mathrm{~m})$ à área de operação do aterro sanitário, porém, sem interferência deste, já na Figura 1 (A) e Figura 1(B), mostrase onde foram amostrados os horizontes $\mathrm{HzA}(0,4 \mathrm{~m}), \mathrm{HzAB}(0,7 \mathrm{~m}), \mathrm{HzB}(1 \mathrm{~m})$ e $\mathrm{HzBC}(3 \mathrm{~m})$, sendo que $\mathrm{Hz}$ representa Horizonte. Para cada $\mathrm{Hz}$ foi coletado 4 cilindros (quadruplicata), para determinação dos parâmetros de interesse (macro e microporosidade, CC e PMP), sendo que a CC foi analisada a $10 \mathrm{KPa}$. Já a CHS foi coletada em triplicata e na vertical, conforme Figura 1 (C).

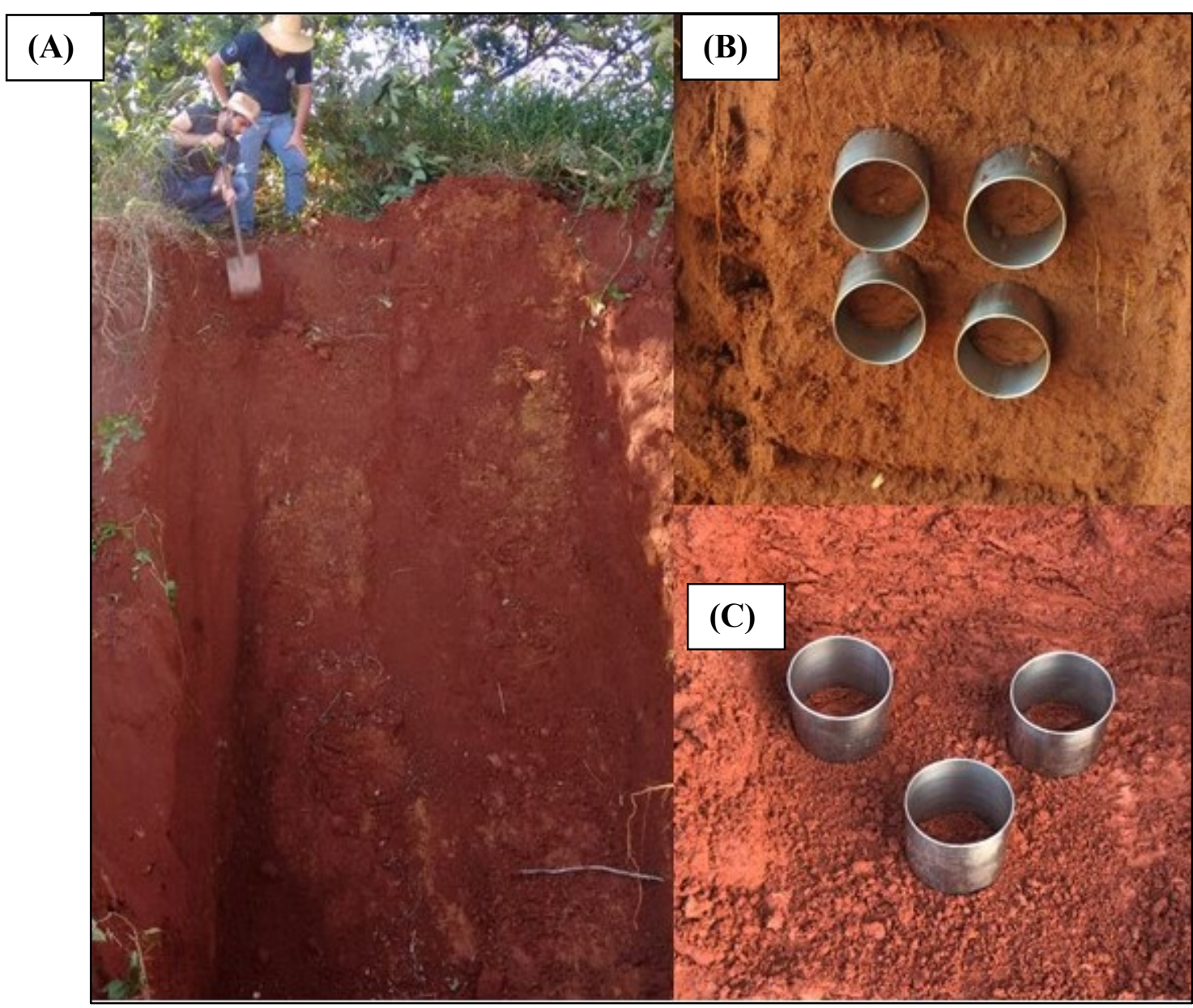

Figura 1 - Perfil do LATOSSOLO VERMELHO Distrófico amostrado (A) e cilindros de coleta para determinação dos parâmetros de interesse (B) e CHS (C).

Fonte: Arquivo pessoal.

Para os testes de permeabilidade do solo in loco foram realizados testes em três pontos próximos as células de disposição de RSU (cerca de seis metros), os quais foram denominados P1, P2 e P3. Os ensaios que visam estimar o coeficiente infiltração realizados para o licenciamento das células, foram elaborados seguindo a NBR 7.229/1993 (ABNT, 1993) por empresas prestadoras de serviços. Esses, indicaram um coeficiente de infiltração inferior a 20 L.m ${ }^{2}$ dia $^{-1}$ (GEAB 
AMBIENTAL, 2006; AGRÍCOLA PAMPEANA, 2012) em ambos os testes. Assim, não foram realizados esses ensaios nessa pesquisa. Os valores de referência para esse ensaio estão ilustrados na Tabela 2 .

Tabela 2 - Faixa de variação e classificação dos coeficientes de infiltração conforme NBR 7.229/1993.

\begin{tabular}{|c|c|c|c|}
\hline Faixa & Constituição provável do solo & $\begin{array}{l}\text { Coeficiente de } \\
\text { infiltração } \\
\left(\mathrm{L} \cdot \mathrm{m}^{2} \text { dia }^{-1}\right)\end{array}$ & $\begin{array}{l}\text { Absorção } \\
\text { relativa }\end{array}$ \\
\hline 1 & $\begin{array}{l}\text { Rochas, argilas compactas de cor branca cinza ou preta, variando a } \\
\text { rochas alteradas e argilas mediamente compactas de cor avermelhada }\end{array}$ & Menor que 20 & Impermeável \\
\hline 2 & $\begin{array}{l}\text { Argilas de cor amarela, vermelha ou marrom mediamente compactas, } \\
\text { variando a argilas pouco siltosas e/ou arenosas }\end{array}$ & 20 a 40 & $\begin{array}{c}\text { Semi- } \\
\text { permeável }\end{array}$ \\
\hline 3 & $\begin{array}{c}\text { Argilas arenosas e/ou siltosas, variando a areias argilosas ou siltes } \\
\text { argilosos de cor amarela, vermelha ou marrom }\end{array}$ & 40 a 60 & Vagarosa \\
\hline 4 & $\begin{array}{l}\text { Areia ou silte argiloso, ou solo arenoso com húmus e turfas, variando } \\
\text { a solos constituídos predominantemente de areias e siltes }\end{array}$ & 60 a 90 & Média \\
\hline 5 & $\begin{array}{l}\text { Areia bem selecionada e limpa, variando a areia grossa com } \\
\text { cascalhos }\end{array}$ & Maior que 90 & Rápida \\
\hline
\end{tabular}

Fonte: Construído a partir de ABNT (1993).

Para os testes de permeabilidade, foi utilizado o permêametro de Guelph (Figura 2) conforme Reynolds; Elrick e Topp (1983), com a rotina descrita por Santos (2005b). Esse teste é amplamente utilizado em estudos que visam estimar a permeabilidade dos solos (LILLY, 1992; AGUIAR, 2001; SANTOS, 2005b; CELLIGOI et al., 2010b; NICOLLA et al., 2017; MACHADO et al., 2017; DIXON, 2019), cumprindo as exigências propostas pela ASTM - D5126 (2010).

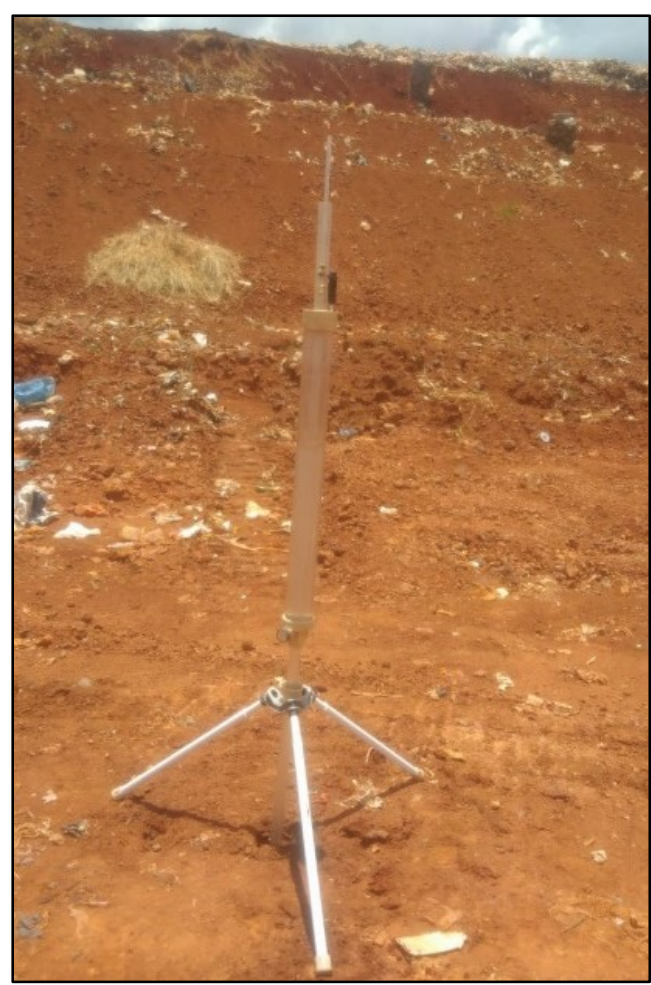

Figura 2 - Testes de permeabilidade de solo realizados utilizando permeâmetro de Guelph. Fonte: Arquivo pessoal. 
Assim, foram realizadas leituras em três pontos de interesse, em dezembro de 2018 com condições climáticas adequadas (presença de sol), com as cargas hidráulicas de cinco e dez cm. Na equação 1 descreve-se a fórmula utilizada para a obtenção da permeabilidade.

$$
\left.K=\left[(0,0041)(X)\left(R_{2}\right)-(0,0054)(X) R_{1}\right)\right]
$$

Onde:

$\mathrm{K}=$ Permeabilidade $\left(\mathrm{cm} . \mathrm{s}^{-1}\right)$;

$\mathrm{X}=$ Constante correspondente a área do tubo externo $\left(35,22 \mathrm{~cm}^{2}\right)$ utilizado;

$\mathrm{R}_{1}=$ Taxa de infiltração estabilizada em $5 \mathrm{~cm}$;

$\mathrm{R}_{2}=$ Taxa de infiltração estabilizada em $10 \mathrm{~cm}$.

\section{RESULTADOS E DISCUSSÃO}

Na Tabela 3 ilustra-se os resultados referentes as amostras do LATOSSOLO VERMELHO Distrófico, nos quatro horizontes analisados (HzA, HzAB, HzB e HzBC), para os parâmetros de porosidade total, microporosidade, macroporosidade, densidade, CC e PMP. Os resultados de porosidade total, micro e macroporosidade apresentaram uma pequena variação quando comparados aos encontrados, nessa mesma área de estudo, por Borba (2016), sendo que o autor descreve os valores médios de 54,69 \%; 47,73\% e 7,33\%, respectivamente. Heath (1982) descreve a porosidade das argilas de cerca de $50 \%$, o que condiz com o material de textura argilosa. Hidrologeologicamente, o autor descreve que as argilas apresentam um rendimento específico de $2 \%$, enquanto a retenção específica é de $48 \%$.

A quantidade e a maneira como os poros estão distribuídos no solo afetam, de forma direta, a infiltração de água no solo, considerando-se a interface entre zona aerada e zona vadosa. De acordo com Brady (1979) os microporos, também chamados de poros capilares, representam os poros responsáveis pela retenção da água no solo, já os macroporos representam os poros responsáveis pela drenagem e aeração do solo. Assim, a retenção específica é baixa para as litologias com poros altamente conectados, tais como areia e o cascalho (tipologias menores que $4 \%$ ); é alta para materiais com um baixo grau de espaços porosos interconectados, tais como as argilas (mais de $40 \%$ ).

Contudo, na visão hidrogeológica, algumas vezes o solo apresenta água renovável, devido à sua agregação (CLEARY, 2007). Com isso, solos argilosos possuem maiores taxas de retenção de água, e consequentemente, uma baixa permeabilidade pelo perfil. Na visão pedológica, Streck et al. (2008), consideram o termo Latossolo, como solos muitos profundos e homogêneos (Figura 1), sendo suas características e classificação de solos bem drenados, normalmente profundos a muito profundos, apresentando no perfil uma sequência de horizontes A - Bw - C. Ainda segundo os autores, 
os Latossolos possuem pouco ou nenhum incremento de argila com a profundidade e apresentam uma transição difusa ou gradual entre os horizontes; por isso mostram um perfil muito homogêneo, onde é difícil diferenciar os horizontes.

Tabela 3 - Informações referentes aos índices físicos analisados em quadruplicata do LATOSSOLO VERMELHO analisado.

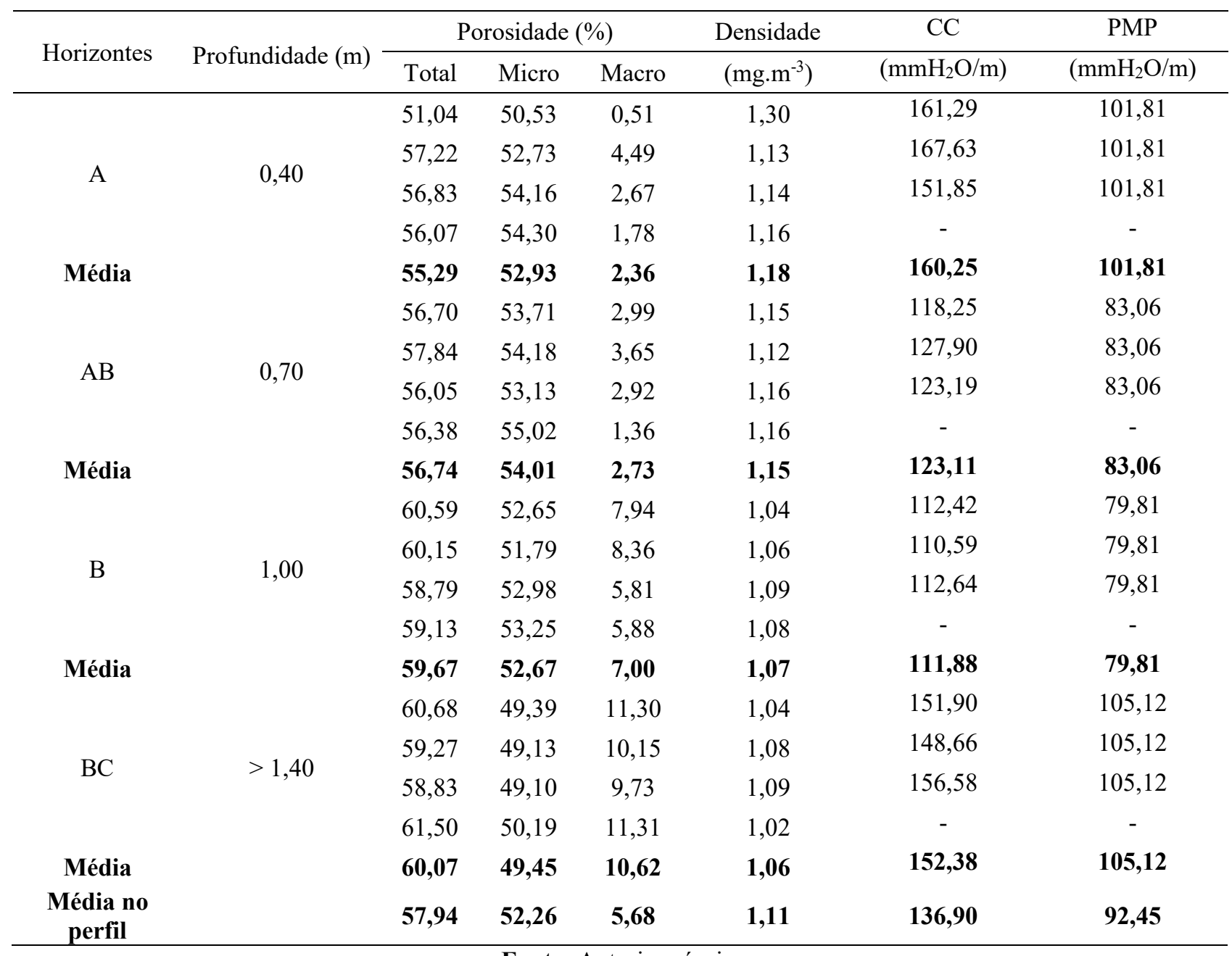

Fonte: Autoria própria.

$\mathrm{Na}$ visão geotécnica, os Latossolos são solos minerais não hidromórficos, com presença de um horizonte B latossólico (EMBRAPA, 2018; STRECK et al., 2008; SALOMÃO; ANTUNES, 1998), onde o horizonte B é conhecido como horizonte maduro, com alta porosidade, conforme mostrado na Tabela 3. Em relação as classes de drenagem, na classificação da EMBRAPA (2018) considera-se bem drenado, aquele em que a água é removida do solo com facilidade, porém, não rapidamente, sendo que apresentam textura média ou argilosa.

Além disso, a franja capilar é mais espessa em solos argilosos e com movimento mais lento, quando comparado a solos arenosos (THOMPSON; TROEH, 2007). Esse fato também foi identificado na flutuação do Nível da Água (NA) nos Poços de Monitoramento (PM). Porém, as 
condições de compactação para operação de células de aterros sanitários, pode alterar essas propriedades. Nesse contexto, Streck et al. (2008) ainda afirmam que os Latossolos possuem condições adequadas em relação a aptidão de disposição final de resíduos, inclusive a instalação de aterros sanitários, isso se deve pela boa capacidade de sorção de contaminantes e pelo fácil controle do escorrimento superficial por práticas mecânicas.

Reinert e Reichert (2006) afirmam que a microporosidade é altamente influenciada pela textura do solo. Nesse sentido, solos argilosos apresentam maior microporosidade (COSTA et al., 2015). Esse fato pode ser observado nesse estudo, no qual se tem uma predominância dos microporos em relação aos macroporos. Esse fator também pode fazer o nível da água ascender por capilaridade nos PM, de acordo com Heath (1982), onde, na área não foi constatado a presença de um lençol freático típico. Isso se deve pelo nível freático local estar estimado em profundidades superiores a 100 m (BORBA, 2016). Uma vez que, não existem informações de captações por poços com registros em um raio de $500 \mathrm{~m}$. Segundo o autor, em uma captação distante $2 \mathrm{~km}$ do empreendimento, o nível da água apresentou profundidade de $130 \mathrm{~m}$. Porém, pode ocorrer algumas formações de água em bolsões isolados, formando aquíferos suspensos temporários (SALOMÃO; ANTUNES, 1998) não conectados, nas camadas argilosas, ascendendo pela capilaridade. Assim, pode ocorrer a percolação do contaminante do aquífero suspenso, até o lençol freático profundo, em longo prazo.

Os valores de CC e PMP estão próximos a aqueles descritos por Pereira et al. (2010) em solos argilosos. Os autores afirmam que a faixa de CC é de 0,39 a $0,55 \mathrm{~m}^{3} \cdot \mathrm{m}^{-3}$ e de 0,30 a $0,45 \mathrm{~m}^{3} \cdot \mathrm{m}^{-}$ ${ }^{3}$ para o PMP. Para os cálculos nos quais se utiliza a CC, foi considerado valor médio de 136,91 $\mathrm{mmH}_{2} \mathrm{O} / \mathrm{m}$. Esse valor foi obtido a partir dos cálculos envolvendo a CC com a profundidade de coleta no perfil.

No que se refere à CHS, na Tabela 4 apresenta-se os valores obtidos. Conforme a NBR 13.896/1997 (ABNT, 1997a), o tipo de solo e a geologia são parâmetros de suma importância em áreas de disposição de resíduos sólidos. Os resultados indicaram que há variabilidade nas profundidades avaliadas, ainda a NBR 13.896/1997 (ABNT, 1997a) aponta que nessas áreas, devese ter um depósito de material homogêneo com coeficiente de permeabilidade inferior a $10^{-6} \mathrm{~cm} \cdot \mathrm{s}^{-1}$, já o subsolo deve possuir coeficiente de permeabilidade inferior a $5 \times 10^{-5} \mathrm{~cm} \cdot \mathrm{s}^{-1}$. A Environmental Guidelines Solid Waste Landfills (2016) relata que as áreas de disposição de RSU devem apresentar CHS inferior a $1 \times 10^{-7} \mathrm{~cm} \cdot \mathrm{s}^{-1}$.

Esses parâmetros estão relacionados ao perfil de infiltração de possíveis contaminantes no solo, além de relacionar-se com a capacidade natural de autodepuração deste. Os valores médios obtidos foram de 5,09 x $10^{-4} \mathrm{~cm} . \mathrm{s}^{-1}$. Além disso, foram coletadas mais duas amostras de solo compactado em dois pontos de coleta, na base do aterro. Os valores médios obtidos foram de 1,27 x 
$10^{-5} \mathrm{~cm} . \mathrm{s}^{-1}$, isso indica que o solo compactado local, se assemelha aos valores permitidos pela NBR 13.896/1997 (ABNT, 1997a). Sendo que, esse será o solo utilizado para a disposição dos resíduos. Celligoi et al. (2006a) analisando a CHS do solo (oriundo de rocha vulcânica) do aterro de Londrina - PR, encontrou valores na ordem de $1,94 \times 10^{-2} \mathrm{~cm}^{-1}{ }^{-1}$, já Pinheiro et al. (2017) em um solo com 62 $\%$ de argila, na região de Santa Maria - RS, descrevem valores na ordem de 3,3 x $10^{-5} \mathrm{~cm} \cdot \mathrm{s}^{-1}$.

Os parâmetros geotécnicos foram descritos por Borba (2016) na área de estudo, onde se tem limite médios de liquidez de 68,83\%, plasticidade de 41,73\%, contração de 28,94 \% e índice de plasticidade de $27,10 \%$.

Tabela 4 - Valores de CHS para os três horizontes de solo analisados.

\begin{tabular}{cc}
\hline Hz & CHS (cm.s.-1) \\
\hline $\mathrm{A}$ & $3,56 \times 10^{-4}$ \\
$\mathrm{~A}$ & $2,22 \times 10^{-3}$ \\
$\mathrm{~A}$ & $2,23 \times 10^{-3}$ \\
\hline Média & $\mathbf{1 , 6 1 \times 1 0 ^ { - 3 }}$ \\
\hline $\mathrm{AB}$ & $3,20 \times 10^{-6}$ \\
$\mathrm{AB}$ & $1,03 \times 10^{-4}$ \\
$\mathrm{AB}$ & $1,28 \times 10^{-5}$ \\
\hline Média & $\mathbf{3 , 9 6 \times 1 0 ^ { - 5 }}$ \\
\hline $\mathrm{B}$ & $1,28 \times 10^{-5}$ \\
$\mathrm{~B}$ & $2,29 \times 10^{-4}$ \\
$\mathrm{~B}$ & $2,98 \times 10^{-4}$ \\
\hline Média & $\mathbf{1 , 9 0 \times 1 0 ^ { - 4 }}$ \\
\hline $\mathrm{BC}$ & $2,65 \times 10^{-5}$ \\
$\mathrm{BC}$ & $1,44 \times 10^{-5}$ \\
$\mathrm{BC}$ & $5,88 \times 10^{-4}$ \\
\hline Média & $\mathbf{2 , 0 9 \times 1 0 ^ { - 4 }}$ \\
\hline Média no perfil & $\mathbf{5 , 0 9 \times 1 0 ^ { - 4 }}$ \\
\hline
\end{tabular}

Fonte: Autoria própria.

Em relação ao teste do coeficiente de infiltração, os resultados foram obtidos em laudos técnicos realizados na área, no momento do licenciamento ambiental das células de operação nos anos de 2006 (GEAB AMBIENTAL, 2006) e 2012 (AGRÍCOLA PAMPEANA, 2012). Os resultados, em ambos os laudos, apresentaram valores inferiores a $20 \mathrm{~L} \cdot \mathrm{m}^{2} \mathrm{dia}^{-1}$. Assim, as taxas de infiltração ficaram entre 20 e $40 \mathrm{~L} \cdot \mathrm{m}^{2} \mathrm{dia}^{-1}$, classificado como faixa 2 (semi-permeável, com a presença de argilas de cores avermelhadas), conforme a NBR 7.669/1993 (ABNT, 1993). Já os valores de permeabilidade do solo saturada, obtido com o permeâmetro de guelph variaram entre 7,3 x $10^{-5}\left(\mathrm{P} 1\right.$ e P2) e $1,5 \times 10^{-5} \mathrm{~cm} \cdot \mathrm{s}^{-1}(\mathrm{P} 3)$. Esses valores de permeabilidade são classificados entre baixo 
e muito baixo (SANTOS, 2005b), e são semelhantes aos encontrados por Callegoi et al. (2010b) na mesma formação geológica. Os resultados estão próximos ao proposto pelas normas NBR 13.896/1997 (ABNT, 1997a) e NBR 15.849/2010 (ABNT, 2010), as quais indicam valores inferiores a $5 \times 10^{-5} \mathrm{~cm} \cdot \mathrm{s}^{-1}$.

Além disso, o solo deve apresentar uma zona não saturada com espessura superior a três m. Heath (1982) define zona não saturada, ou zona insaturada, como a zona subsuperficial usualmente começando na superfície do solo, que contém água e ar. $\mathrm{Na}$ área, a espessura da camada de solo existente varia de 3,7 a 7,5 m (DARIVA AMBIENTAL, 2006), estando de acordo com o proposto pela NBR 13.896/1997 (ABNT, 1997a).

Em relação ao fluxo subterrâneo, Borba (2016) analisou a variação da flutuação do nível da água entre 04/02/2015 e 11/03/2016 (totalizando um ano hidrológico). O autor descreve que a direção do fluxo foi constante durante o período analisado, em direção ao PM03 localizado na cota mais baixa do terreno. Esse fluxo indica que uma possível dispersão de contaminantes se direcionará para esse ponto de monitoramento. Além Disso, na área em questão ocorre a formação de um aquífero suspenso temporário não contínuo (Borba, 2019).

\section{CONCLUSÕES}

As técnicas utilizadas para a estimativa da permeabilidade do solo se mostraram eficientes, seja in situ ou ex situ. Os resultados indicaram que o solo apresenta uma característica argilosa, com predominância de microporos. A permeabilidade do solo compactado apresentou valores semelhantes aos descritos pelas normativas que envolvem os aterros sanitários. Assim, o solo apresenta condições naturais de preservação do meio subterrâneo.

\section{AGRADECIMENTOS}

O presente trabalho foi realizado com apoio da Coordenação de Aperfeiçoamento de Pessoal de Nível Superior - Brasil (CAPES) - Código de Financiamento 001.

\section{REFERÊNCIAS}

ABNT. ASSOCIAÇÃO BRASILEIRA DE NORMAS TÉCNICAS. NBR 15.849: Resíduos sólidos urbanos - Aterros sanitários de pequeno porte - Diretrizes para localização, projeto, implantação, operação e encerramento. Rio de Janeiro: ABNT, 2010. 24p.

ABNT. ASSOCIAÇÃO BRASILEIRA DE NORMAS TÉCNICAS. NBR 13.896: Aterros de resíduos não perigosos - Critérios para projeto, implantação e operação. Rio de Janeiro: ABNT, 1997. $12 \mathrm{p}$. 
ABNT. ASSOCIAÇÃO BRASILEIRA DE NORMAS TÉCNICAS. NBR 8.419: Apresentação de projetos de aterros sanitários de resíduos sólidos urbanos. Rio de Janeiro: ABNT, 1992. 7p.

ABNT. ASSOCIAÇÃO BRASILEIRA DE NORMAS TÉCNICAS. NBR 7.229: Projeto, construção e operação de sistemas de tanques sépticos. Rio de Janeiro: ABNT, 1993. 15p.

AGRÍCOLA PAMPEANA. Laudo técnico de ensaio de solo e descrição morfológica - Relatório interno. Seberi: Agrícola Pampeana, 2012. 14p.

AGUIAR, A. B. O emprego do permeâmetro de guelph na determinação da permeabilidade do solo, de camadas de lixo e sua cobertura. 2001. 67 f. Dissertação (Mestrado em Engenharia Civil) - Universidade Federal de Rio de Janeiro, Rio de Janeiro, 2001.

ASTM. D5126-16e1, Standard Guide for Comparison of Field Methods for Determining Hydraulic Conductivity in Vadose Zone. ASTM International: West Conshohocken, PA, 2016. $12 \mathrm{p}$.

BORBA, W. F. Vulnerabilidade natural à contaminação da água subterrânea em área ocupada por aterro sanitário em Seberi - RS. 2016. 174 f. Dissertação (Mestrado em Engenharia Ambiental) - Universidade Federal de Santa Maria, Santa Maria, 2016.

BRADY, N. C. Natureza e propriedades dos solos. 5. ed. São Paulo: F. Bastos, 1979. 64 p.

BRADY, N. C.; WEIL, R. R. Elementos da natureza e propriedades dos solos. 3. Ed. Porto Alegre: Brookman, 2013. 679 p.

CELligOI, A. LAMÔNICA, D.; MACHADO, A. de. C.; SOUSA, R. V. B. de; MEDEIROS, H. R. Determinação das condutividades hidráulicas das zonas saturada e não saturada do aquífero freático nas adjacências do aterro controlado de Londrina. In: CONGRESSO BRASILEIRO DE ÁGUAS SUBTERRÂNEAS. 14., 2010, Curitiba. Anais... Curitiba: ABAS, 2010a. p. 1-13.

CElligoI, A.; SOUSA, R. V. B.; MEDEIROS, H. R. LAMÔNICA, D.; MACHADO, A. C. Utilização do permeâmetro de guelph da determinação da condutividade hidráulica da zona não saturada do aquífero freático nas imediações do lixão de Londrina - PR. In: CONGRESSO BRASILEIRO DE ÁGUAS SUBTERRÂNEAS. 14., 2010, Curitiba. Anais... Curitiba: ABAS, 2010b. p.1-14.

CLEARY, R. W. Águas subterrâneas. 1. ed. Porto Alegre: ABRH, 2007. 117p.

COSTA, C. D. O.; ALVES, M. C.; SOUSA, A. de P. Movimento de água e porosidade dos solos de uma sub-bacia hidrográfica no noroeste do estado de São Paulo. Revista Irriga, Botucatu, v. 20, n. 2, p. 304-318, 2015.

CPRM. Companhia de Pesquisa de Recursos Minerais. Mapa geológico do Estado do Rio Grande do Sul. Porto Alegre: CPRM, 2006.

DARIVA AMBIENTAL. Relatório técnico de instalação de poços de monitoramento. Frederico Westphalen: Dariva Ambiental, 2006. 9p. 
DIXON, N.; CROSBY, C. J.; STIRLING, R.; HUGHES, P. N.; SMETHURST, J.; BRIGGS, K; HUGHES, D.; GUNN, D.; HOBBS, P.; LOVERIDGE, F.; GLENDINNING, S.; DIJKSTRA, T.; HUDSON, A. In situ measurements of near-surface hydraulic conductivity in engineered clay slopes. Quarterly Journal of Engineering Geology and Hydrogeology, v. 52, p. 123-135, 2019.

. ENVIRONMENT PROTECTION AGENCY. Environmental Guidelines Solid waste landfills. EPA: Sydney, 2016. 95p.

EMBRAPA. EMPRESA BRASILEIRA DE PESQUISA AGROPECUÁRIA. Manual e métodos de análise de solo. 1. ed. Brasília: EMBRAPA, 2018. 573p.

GEAB AMBIENTAL. Projeto de determinação da capacidade de adsorção do solo - Ensaio de infiltração - Obra GEAB 005/2006. Passo Fundo: GEAB, 2006. 16p.

GOMES, L. P.; KOHL, C. A.; SOUZA, C. L. de L.; REMPE, N.; MIRANDA, L. A. S.; MORAES, C. A. M. Avaliação de aterros sanitários de resíduos sólidos urbanos precedidos ou não por unidades de compostagem. Eng. Sanit. Ambient, v. 20, n. 3, p. 449-462, 2015.

HEATH, R. C. Basic ground-water hidrology. 1. ed. Denver: Water supply paper 2240 USGS, 1982. 86p.

LILLY, A. The determination of field-saturated hydraulic conductivity in some Scottish soils using the Guelph permeameter. Soil Use and Management, v. 10, n. 2, p. 72-78, 1994.

MACHADO, J. L. F.; FREITAS, M. A. Projeto mapa hidrogeológico do Estado do Rio Grande do Sul: escala 1:750.000, relatório final. Porto Alegre: CPRM, 2005.

MACHADO, S. L.; CARVALHO, Z. S.; CARVALHO, M. F.; MARIZ, D. F. Field Permeability tests using ornganic liquids in compacted Brasilian soils. Soil and Rocks, São Paulo, v. 39, n. 3, p. 301$314,2016$.

MARQUES, J. D.; TEIXEIRA, W. G.; REIS, A. M.; CRUZ JÚNIOR, O.; MARTINS, G. C. Avaliação da condutividade hidráulica saturada utilizando dois métodos de laboratório numa topossequência de solos amazônicos em diferentes coberturas vegetais. Acta Amazônica, Manaus, v. 38, n. 2, p. 193-206, 2008.

MORENO, J. A. Clima do Rio Grande do Sul. Secção de Geografia. Secretaria da Agricultura. 1. ed. Porto Alegre, 1961. 42p.

PEREIRA, L. S.; VALERO, J. A. J.; BUENDÍA, M. R. P.; MARTÍN-BENITO, J. M. T. El riego e sus tecnologías. 1. ed. Albacete: CREA-UCLM, 2010, 296p.

PINHEIRO, R. J. B.; NUMMER, A. V.; RAUBER, A. C. Determinação da condutividade hidráulica das principais unidades geológico-geotécnicas de Santa Maria - RS. Geociências, São Paulo, v. 36, n. 2, p. 347-363, 2017.

PRIYANK, G.; ALAM, J.; MUZZAMMIL, M. Influence of thickness and position of the individual layer on the permeability of the stratified soil. Perspectives in Science. v. 8, p. 757-759. 2016.

REINERT, D. J.; REICHERT, J. M. Coluna de areia para medir a retenção de água no solo: protótipos e teste. Ciência Rural, v. 36, n. 6, p. 1931-1935, 2006. 
REYNOLDS, W. D.; ELRICK, D. E.; TOPP, G. C. A reexamination of the constant head well permeameter method for measuring saturated hydraulic conductivity above the water table. 1. Soil Science, v. 136, n. 4, p. 250-268, 1983.

RODRIGUEZ, T. T.; WEISS, L. A.; TEIXEIRA, R. S.; BRANCO, C. J. M. C. Permeabilidade de Solo Laterítico por Diferentes Métodos. Ciências Exatas e Tecnológicas, v. 36, n. 2, p. 17-32. 2015.

ROSS, J. L. S. Relevo Brasileiro: uma nova proposta de classificação. Revista do Departamento de Geografia, São Paulo, v. 4, p. 25-39, 1985.

SAlOMÃO, F. X. T.; ANTUNES, F. S. Solos. In: OLIVEIRA, A. M. S.; BRITO, S. N. A. Geologia de Engenharia. São Paulo: ABGE, 1998. cap. 6. 587p.

SANTOS, M. M. Avaliação hidrogeológica para determinação da vulnerabilidade natural do aquífero freático em área selecionada na cidade de Londrina - PR. 2005. 159 f. Dissertação (Mestrado em Geociências) - Universidade do Estado de São Paulo, Rio Claro, SP, 2005b.

SEMA. SECRETARIA DO MEIO AMBIENTE DO ESTADO DO RIO GRANDE DO SUL. Mapa das bacias hidrográficas e municípios do Rio Grande do Sul. Porto Alegre: SEMA, 2004.

SINGH, V. K.; KUMAR, D.; KASHYAP, P. S.; SINGH, P. K.; KUMAR, A.; SINGH, S. K. Modelling of soil permeability using different data driven algorithms based on physical properties of soil. Journal of Hydrology, v. 580, p. 124223-124242, 2020.

SOTÉRIO, P. W.; PEDROLLO, M. C. R.; ANDRIOTTI, J. L. Mapa de isoietas do Rio Grande do Sul. In: XVI SIMPÓSIO BRASILEIRO DE RECURSOS HÍDRICOS, 16., 2005. João Pessoa. Anais... João Pessoa: ABRH, 2005. p. 1-5.

STRECK, E. V.; KÄMPF, N.; DALMOLIN, R. S. D.; KLAMT, E.; NASCIMENTO, P. C.; SCHNEIDER, P.; GIASSON, E.; PINTO, L. F. S. Solos do Rio Grande do Sul. 1. ed. Porto Alegre: EMATER/RS - ASCAR, 2008. 222p.

THOMPSON, L. M.; TROEHH, F. R. Solos e fertilidade do solo. 1. ed. São Paulo: Andrei, 2007. $718 \mathrm{p}$. 